\title{
Regime de colaboração: duas experiências de organização cooperativa na área de educação
}

\author{
Ubirajara Couto Lima* \\ Universidade Estadual do Sudoeste da Bahia \\ Tiago Guedes Barbosa do Nascimento Neves** \\ Universidade do Porto
}

Resumo Este artigo refere-se a resultado parcial de pesquisa de doutoramento cujo objetivo mais amplo é identificar e analisar as experiências de Arranjos de Desenvolvimento da Educação no estado da Bahia. Apoiado numa abordagem qualitativa e tendo como estratégia metodológica o estudo de caso, este artigo objetiva apresentar duas experiências de organização cooperativa, caracterizando-as e problematizando a sua articulação com o instituto do regime de colaboração, sobretudo no tocante ao compartilhamento de competências políticas, técnicas e financeiras. Os resultados preliminares evidenciam que, apesar de serem modelos exitosos de organização cooperativa, há uma flagrante necessidade de ações coordenadoras e indutivas da União e dos estados, que no caso da Bahia, no plano intergovernamental, tem um inexpressivo papel na articulação federativa com os municípios.

PALAVRAS-CHAVE: Regime de colaboração; Associativismo territorial; Educação. 


\title{
Collaboration regime: two experiences of cooperative organization in the area of education
}

\begin{abstract}
This article refers to a partial result of doctoral research whose main objective is to identify and analyze the experiences of Education Development Arrangements in the state of Bahia. Based on a qualitative approach and having as a methodological strategy the case study, this article aims to present two experiences of cooperative organization, characterizing them and problematizing their articulation with the institute of the collaboration regime, especially with regard to the sharing of political, technical and and financial. The preliminary results show that, despite being successful models of cooperative organization, there is a flagrant need for coordinating and inductive actions of the Union and the states, which in the case of Bahia, in the intergovernmental plan, has an inexpressive role in the federative articulation with the municipalities.
\end{abstract}

KEYWORDS: Collaboration regime; Territorial associativism; Education.

\section{Introdução}

Ao longo dos últimos anos, a ativa participação do movimento Todos pela Educação (TPE) nos processos de formulação e implementação de políticas educacionais junto ao governo federal brasileiro, nomeadamente sobre os Arranjos de Desenvolvimento da Educação ${ }^{1}$ (ADEs), tem fomentado um intenso campo de disputa, de natureza teórica e prática: de um lado os reformadores empresariais defendendo os ADEs como sinônimo do regime de colaboração e envidando esforços para esvaziar a possibilidade política de sua regulamentação; de outro, os profissionais da educação, a partir de sua atuação em vários órgãos e instâncias, envidando esforços para compreender nosso complexo pacto federativo e empenhando-se em buscar alternativas de financiamento e possibilidade de fóruns interfederativos que possam se institucionalizar e servir de base para a lei complementar do regime de colaboração, que assegure a oferta de educação em quantidade e qualidade com base no princípio da equalização.

É nesse campo de disputa que se insere a aludida pesquisa cujo objetivo inicial, e do qual trata este trabalho, é identificar as experiências de ADEs no estado da Bahia, analisando de que modo essas experiências se articulam com o instituto do regime de colaboração, sobretudo no tocante ao compartilhamento de competências políticas, técnicas e financeiras.

No tocante às opções metodológicas, tendo como base os objetivos propostos, foi adotada como abordagem a metodologia qualitativa, enquanto o caminho, ou estratégia metodológica, escolhido para a condução da pesquisa foi o estudo de caso. Desse modo, estamos realizando uma pesquisa de caráter empírico-descritivo, instrumentalizada pela coleta e análise de documentos dos ADEs (regimentos, mapas estratégicos/Plano de Ações Articuladas e indicadores educacionais locais), acompa- 
nhamento de reuniões, bem como entrevistas a gestores, educadores e secretários de educação dos municípios que integram os Arranjos analisados.

Para a interpretação dos dados foi adotada a proposta hermenêutica-dialética que pressupõe, segundo Thompson (1995), três níveis interligados de abordagem: a análise sócio-histórica, a análise discursiva e a interpretação/re-interpretação, que realiza a síntese, ou o concreto pensado. Esta opção se justifica por considerar que a hermenêutica dialética possibilita a compreensão do texto, da fala, do depoimento, como resultantes de um processo social e de um processo de conhecimento, cada qual com significado específico, porém articulados entre si.

\section{Duas experiências de organização cooperativa na educação}

\section{O arranjo de desenvolvimento da Chapada Diamantina e Semiárido}

A Chapada Diamantina é uma cadeia montanhosa localizada no estado da Bahia, Brasil, e constitui um dos vinte e sete Territórios de Identidade do referido estado. Segundo a publicação Perfil dos Territórios de Identidade do Estado da Bahia (2015), o Território de Identidade Chapada Diamantina possui população de 371,8 mil pessoas, de acordo com o Censo 2010 do IBGE, e extensão total de 30,4 mil quilômetros quadrados, sendo composto por 24 municípios.

No âmbito da educação, um dos avanços verificados no Território Chapada Diamantina foi a redução do número de analfabetos entre 2000 e 2010. A taxa caiu de $28,3 \%$ para $20,8 \%$ para a população com idade superior a 15 anos. Note-se, porém, que é superior à média baiana, que alcança $16,3 \%$. O acesso à educação na faixa etária entre 6 e 14 anos caminha para a universalização no território, tendo passado de $90 \%$ para $97,3 \%$ entre 2000 e 2010. Com relação à faixa etária entre 4 e 5 anos, a universalização ainda é um desafio, embora o avanço no mesmo período tenha sido expressivo, passando de 42,9\% para 79,7\% (BAHIA, 2015).

É nesse contexto que, no ano de 1997, teve início o Projeto Chapada, constituído por um grupo formado por educadores, profissionais liberais, membros de organizações da sociedade civil e gestores municipais, cuja pergunta inquietadora era: "como uma rede de municípios e educadores pode transformar para sempre a situação educacional em determinada região? ”. A região, em questão, apresentava limitações que incluíam a precária formação de professores, a ausência de coordenadores pedagógicos capacitados para levar a cabo as avaliações pertinentes, e os critérios inadequados de seleção dos diretores. Em resposta aos desafios, nasceu a iniciativa que combinava a formação continuada de coordenadores pedagógicos e ações de mobilização social em prol da melhoria da qualidade da educação pública na região da Chapada Diamantina, estado da Bahia (OLIVEIRA; MEIRELLES, 2012, p. 114).

Entre os anos de 1997 e 1998, com o apoio do "Programa Ver para Crer" (criado em 1995), vinculado ao Instituto Natura, a Associação de Pais e Alunos do Colégio Estadual de Primeiro Grau de Caeté-Açu (distrito rural do município de Palmeiras, Bahia) realizou um Programa de Desenvolvimento e Auxílio ao Professor, 
voltado para a formação de professores do Ensino Fundamental, e com foco em referenciais teóricos construtivistas, além de recursos e instrumentos para auxiliar a prática pedagógica.

Os resultados da aludida ação foram muito expressivos, refletindo uma significativa redução nos índices de evasão e repetência, aumento da frequência escolar, melhoria da qualidade da escrita e da oralidade dos alunos, avanços no plano de cargos e salários, e na reestruturação física das escolas. A partir da divulgação desses resultados, outros municípios demonstraram interesse em participar do Projeto.

Entre os anos de 1999 e 2000, foi formada uma comissão responsável por elaborar o Projeto Chapada, congregando secretarias municipais de doze municípios da Chapada Diamantina, associações locais, professores, representantes da Secretaria Estadual de Educação e do "Programa Crer para Ver". Para tanto, foram realizados encontros mensais em cada um dos municípios, e na oportunidade eram discutidos os diagnósticos locais, traçadas as metas para o Projeto e definidas as principais ações, sempre com a preocupação de explicitar o caráter apartidário da iniciativa.

A conclusão da elaboração do Projeto coincidiu com o período eleitoral, o que incentivou a realização de debates nos municípios com a participação dos professores e da população em geral. Vale ressaltar que esses debates ganharam uma configuração de plataforma popular, o que contribuiu para que mesmo nos casos em que houve alternância do grupo político municipal, não houvesse um abandono do compromisso com o Projeto.

Destacou-se também nesse período a "Campanha Chapada e Semiárido pela Educação" (oficinas, rodas de conversa, fóruns e seminários de Educação) que, nas palavras de Oliveira e Meirelles (2012, p. 121), "colabora com uma pauta política e estratégica visando ao desenvolvimento do país” ao representar a mobilização de uma rede que articula vários municípios, na perspectiva da resolução de problemas e na busca de alternativas próprias, e extrapola a dimensão pedagógica para contribuir com a implementação de políticas públicas em geral. Essas ações continuaram sendo desenvolvidas em conjunto com parceiros, consultores, formadores, coordenadores e ONGs.

No período compreendido entre os anos 2000 e 2003 algumas ações importantes aconteceram no Projeto Chapada, incluindo assinatura pública do compromisso com a proposta pelos prefeitos eleitos; a realização de um diagnóstico de marco zero na rede escolar dos doze municípios sobre a construção do sistema de escrita; criação de espaços para os coordenadores pedagógicos debaterem aspectos relativos à organização do trabalho e à constituição de grupos, e de transporte, para que os coordenadores pudessem acompanhar as escolas, inclusive aquelas de difícil acesso; a reivindicação de participação no Projeto por parte dos diretores escolares dos municípios integrantes.

Entre os anos de 2004 e 2006, tornou-se crescente a mobilização pela Educação, ao passo em que surgiu o debate sobre a necessidade de institucionalização do trabalho. Desse modo, um grupo constituído por representantes das secretarias de Educação, associações e coordenadores deu início à elaboração do estatuto do que veio a ser o Instituto Chapada de Educação e Pesquisa (ICEP). Esse novo momento fez 
com que o Projeto Chapada focalizasse as suas ações na formação continuada, na consolidação de espaços de formação permanente nas escolas por meio da construção de equipes colaborativas de trabalho, bem como estimulou a construção e implantação de projetos institucionais articulados ao projeto político-pedagógico das escolas e redes municipais. Como consequência do trabalho desenvolvido e dos bons resultados apresentados, houve o ingresso de mais quinze municípios no Projeto Chapada, incluindo dois do Território Semiárido.

O modelo organizacional adotado pelo ICEP foi composto de maneira que priorizasse o principal legado do Projeto Chapada: a participação coletiva. Desse modo, a assembleia de sócios-fundadores, composta por todos que participaram das resoluções sobre o Instituto, tornou-se a principal instância decisória. Ademais, todas as secretarias de educação dos municípios membros passaram a integrar o Comitê Estratégico do ICEP, enquanto dois profissionais da área de Educação de cada município foram indicados para compor a Comissão Permanente de Avaliação do Projeto Chapada.

Entre os anos de 2007 e 2012, foram definidos ciclos e fases de permanência das ações do Projeto, à medida em que foi sendo construída uma matriz avaliativa dos processos. Já em 2009, três municípios constituintes do ICEP atingiram os melhores resultados do estado da Bahia no Índice de Desenvolvimento da Educação Básica (IDEB). Além do mais, avaliações externas indicaram que o ciclo inicial da alfabetização (6 a 8 anos de idade) estava sendo garantido para uma média de $88 \%$ dos alunos.

A consolidação das ações desenvolvidas contribuiu para bons resultados e também para a conquista de novos parceiros, incluindo o Ministério da Educação, que garantiu o apoio institucional para a publicação de material pedagógico - produto da sistematização das práticas e voltado para a formação continuada - intitulado "Coordenador pedagógico: função, rotina e prática".

Atualmente, além da Assembleia Geral, constituída pelos seus sócios-fundadores, sócios-efetivos e sócios-colaboradores, o ICEP conta com: uma Equipe Executiva, responsável pela gestão da organização e também pela mobilização de recursos; uma Diretora pedagógica, três Coordenadoras e um grupo de Formadores, ambos responsáveis pelo desenvolvimento das ações pedagógicas, que são acompanhadas pelo Comitê Estratégico, formado pelos/pelas secretários/as de educação e suas equipes técnicas; um Conselho Consultivo, composto por profissionais de notório saber nas áreas de educação e gestão; e um Conselho Fiscal, responsável por acompanhar o desenvolvimento e utilização dos recursos financeiros.

O horizonte de atuação do ICEP foi significativamente ampliado, de modo que suas ações estão sendo desenvolvidas em vinte e nove municípios, incluindo três de dois estados vizinhos à Bahia: Alagoas e Pernambuco. Dados de 2014 indicam que só no Território Chapada as ações envolveram um total de: 3.816 professores; 378 coordenadores pedagógicos; 237 diretores escolares; 61 diretores pedagógicos e/ ou supervisores técnicos; 15 secretários de educação e 15 prefeitos. E com relação às ações no Ensino Fundamental I, 61.964 estudantes de 468 escolas públicas munici- 
pais foram alfabetizados de acordo com a metodologia desenvolvida pelo ICEP e os municípios membros.

No tocante aos recursos financeiros, segundo o Relatório Financeiro de 2010 e o Relatório de Auditoria referente às demonstrações financeiras de 2010/2011, o Instituto Chapada é uma Organização da Sociedade Civil de Interesse Público (OS$\mathrm{CIP}$ ), que tem como fontes de recursos doações, auxílios, legados e subvenções. Com relação à administração pública, o ICEP firmou termo de parcerias com 24 municípios, o que vem garantindo receitas como subvenção. Já em relação à iniciativa privada, na sua lista de parceiros constam as seguintes empresas: Instituto Natura/Natura Cosméticos S.A.; Banco Itaú BBA S.A.; Instituto Península; Odebrecht TransPort/Concessionária Rota dos Coqueiros; Instituto C\&A; Fundação Lemann; e BSC/Copener; e Ashoka/Empreendedores Sociais.

\section{O fórum de secretários de educação dos municípios do Vale do Jiquiriçá - EDUCAVALE}

Segundo a publicação Perfil dos Territórios de Identidade do Estado da Bahia (2015), o Território de Identidade Vale do Jiquiriçá localiza-se no centro sul da Bahia e possui extensão total de 10,4 mil quilômetros quadrados. É composto por 20 municípios. A população total do território é de 274,9 mil habitantes. O maior município é Jaguaquara, com população de 51 mil habitantes, de acordo com o Censo 2010 do IBGE. A análise dos dados demográficos indica que a população do território não cresceu entre os anos de 2000 e 2010. A população urbana se expandiu na mesma média geral da Bahia $(0,7 \%)$, mas a rural encolheu $0,8 \%$.

Com relação à Educação, os dados censitários mostram que, entre 2000 e 2010, o Vale do Jiquiriçá conseguiu reduzir o analfabetismo, que recuou de 30,9\% para 25,4\%. Apesar da redução, o território ainda está muito aquém da média baiana, que em 2010 alcançou 16,3\%. Nenhum município tem percentual de analfabetos com mais de 15 anos inferior a $20 \%$ da população. $\mathrm{O}$ acesso à educação na faixa entre $6 \mathrm{e}$ 14 anos, no entanto, é mais positivo e acompanha a tendência da Bahia. Entre 2000 e 2010 o acesso se ampliou de 92\% para 97\% das crianças, superando a média estadual de 96,9\% (BAHIA, 2015).

É nesse contexto que emerge o Fórum de Secretários de Educação dos Municípios do Vale do Jiquiriçá (EDUCAVALE), enquanto uma organização ligada à Associação dos Municípios do Vale do Jiquiriçá (MERCOVALE), e que visa funcionar como um espaço que promova, incentive, e viabilize a cooperação intermunicipal, intergovernamental e sociedade civil organizada na área educacional. O Fórum EDUCAVALE foi constituído originalmente pelos municípios filiados ao MERCOVALE, cuja concepção aconteceu no ano de 2009, como iniciativa exclusiva dos mandatários municipais, a partir do entendimento sobre a importância da articulação como um mecanismo valioso na busca de soluções para problemas comuns, bem como a adoção de uma cultura apoiada na troca de experiências sobre boas práticas. 
Já a concepção do EDUCAVALE deu-se no ano de 2010, em virtude da demanda dos municípios para garantir aos seus professores a oportunidade de cursar uma licenciatura numa Instituição de Ensino Superior Pública (IESP), através do Programa Nacional de Formação de Professores (PARFOR). A maior dificuldade enfrentada pelos municípios residia na obrigação de garantir a contrapartida dentro do referido Programa, nomeadamente incumbir-se do deslocamento dos professores até os polos formadores (sedes das Universidades), assegurando a estes a hospedagem, a alimentação, o transporte, e ainda um/a professor/a substituto/a por um período que varia de cinco a oito dias consecutivos por mês, durante os três anos de formação. Esta peleja constituiu-se na pedra angular do Fórum EDUCAVALE, à medida que exigiu dos prefeitos e dos secretários municipais de Educação a articulação necessária entre si, e com as instituições que lhes pudessem auxiliar na construção coletiva de uma solução para os problemas, a saber: Coordenação de Aperfeiçoamento de Pessoal de Nível Superior (CAPES), Instituto Anísio Teixeira (IAT), Secretaria Estadual de Educação (SEC), Universidades Estaduais, Fórum Estadual de Formação Docente, e Conselho Estadual de Educação (CEE).

As tratativas em questão possibilitaram a criação de Polos de Formação de Professores regionalizados no Vale do Jiquiriçá, oferecendo inicialmente o curso de Pedagogia, para o qual havia uma demanda conjunta por mil vagas, conforme levantamento realizado em cada município. O planejamento inicial indicava a necessidade de três Polos, mas com o desdobramento das discussões e diante de novas demandas, avançou-se para a concretização de sete Polos, assim distribuídos: Brejões e Nova Itarana (UNEB); Elísio Medrado e São Miguel das Matas (UNEB); Itatim e Santa Terezinha (UNEB); Jaguaquara, Irajuba, Itiruçú e Itaquara (UESB); Maracás e Lajedo do Tabocal (UNEB); Planaltino (UNEB); Santa Inês, Cravolândia, Ubaíra e Jiquiriçá (UESB).

Ainda no ano de 2010, registrou-se outra grande mobilização por parte do Fórum, que após apresentar suas necessidades à Secretaria de Educação do Estado (SEC), assinou convênios para garantir assessoria aos municípios no tocante à elaboração dos Planos Municipais de Educação e Planos de Carreiras. Na sequência, foram realizadas reuniões regionalizadas no Vale do Jiquiriçá, em parceria com técnicos da Empresa Baiana de Desenvolvimento Agrário (EBDA) e Ministério do Desenvolvimento Agrário (MDA), congregando secretários municipais de Educação, nutricionistas, secretários de Agricultura, para em conjunto discutirem estratégias para que os municípios implementassem a Lei 11.947/2009, que estabelece a aplicação de no mínimo 30\% dos recursos da alimentação escolar para aquisição de produtos da agricultura familiar.

Ainda no decorrer do ano de 2010, em Assembleia Geral do Fórum, composta pelos secretários municipais de Educação e instância máxima de deliberação, foi aprovado o Regimento Interno, no qual constam como finalidades principais do EDUCAVALE: promover a troca de experiências administrativas na área educacional entre os municípios associados; mobilizar os municípios, visando defender e reivindicar os interesses das administrações municipais da Região na área educacional, junto às demais esferas de Governo, bem como frente à sociedade; auxiliar e estimular a 
discussão e a implementação, junto aos municípios associados, de políticas públicas educacionais visando o desenvolvimento local e regional (JAGUAQUARA, 2010).

O referido Regimento prevê uma coordenação eleita entre os secretários de Educação, composta por coordenador/a geral, vice-coordenador/a e secretário/a executivo/a, com mandato de um ano, ocorrendo a eleição sempre no mês de aniversário do Fórum. Ao longo de sua existência, as reuniões do EDUCAVALE acontecem sempre de forma itinerante e com periodicidade mensal. E seu planejamento sempre priorizou atividades ampliadas, envolvendo, além de reuniões entre os secretários de educação, encontros específicos com técnicos pedagógicos, administrativos, diretores, coordenadores pedagógicos e conselheiros municipais de educação. Ademais, são muito comuns atividades paralelas abrangendo dirigentes de Cultura e coordenadores de pontos de Cultura do Vale do Jiquiriçá.

Entre os anos de 2011 e 2012, alguns encaminhamentos importantes foram deliberados, especificamente sobre: implementar o ensino fundamental de nove anos; criação de um grupo de trabalho EDUCAVALE/UFRB para formulação de uma proposta de formação continuada na área de Educação Especial para os municípios do Fórum; garantir que cada município tenha um educador responsável pela Educação Especial; revisar as propostas pedagógicas e curriculares garantindo a adequação das mesmas ao Ensino Fundamental de 9 anos; garantir espaço específico dentro do EDUCAVALE para diretores e coordenadores pedagógicos discutirem questões relacionadas à aprendizagem; solicitar inclusão na pauta da União Nacional dos Dirigentes Municipais de Educação (UNDIME), Seção Bahia das temáticas da Educação Especial, do Campo e Sistema Integrado de Monitoramento Execução e Controle do Ministério da Educação (SIMEC) para discussão de parcerias com a Secretaria Estadual da Educação.

Nesse período, os resultados do Índice de Desenvolvimento da Educação Básica foram divulgados e apontaram que todos os municípios do Território de Identidade do Vale do Jiquiriçá superaram as metas previstas para o Ensino Fundamental/ Séries Iniciais. Os resultados demonstraram que a qualidade da educação nesta etapa de ensino melhorou, e o município de Itatim foi o que alcançou a maior nota, seguido dos municípios de Amargosa e Elísio Medrado. No entanto, todos os outros tiveram melhoras em seus resultados.

Com relação aos resultados do Ensino Fundamental/Séries Finais, dos 22 municípios à época vinculados ao Fórum, apenas 11 conseguiram superar as metas estabelecidas. O município de Planaltino teve a maior nota, superando inclusive a média nacional; em seguida, os municípios de Itaquara e São Miguel das Matas. Vale o destaque de que nesta etapa de ensino o desempenho foi preocupante em todo o país, com poucos municípios conseguindo superar as metas previstas.

Ainda nesse período, contando com o incondicional apoio da União Nacional dos Conselheiros Municipais de Educação (UNCME), foram realizadas algumas ações importantes voltadas à garantia da qualidade da educação, sobretudo no tocante ao direito de aprender dos/as alunos/as: encaminhamento para UNCME das deman- 
das de formação de Conselheiros Municipais de Educação (CME); constituição de um protocolo mínimo para garantir o funcionamento dos conselhos; organização de oficinas regionalizadas para os conselheiros sobre elaboração de pareceres e resoluções; criação do Polo da UNCME do Vale do Jiquiriçá; e criação/reformulação dos sistemas municipais de educação para os municípios que ainda não tinham realizado.

Ao longo desses anos, o EDUCAVALE manteve-se articulado ao Fórum Estadual de Educação (FEE), criado em 2011, e responsável pela mobilização do estado da Bahia e seus municípios para a criação e implementação do Plano Estadual e Planos Municipais de Educação, bem como a organização das Conferências Municipais, Territoriais e Estadual de Educação, visando a realização da Conferência Nacional de Educação (CONAE), realizada no ano de 2014, cujo tema foi "O Plano Nacional de Educação na Articulação do Sistema Nacional de Educação: Participação Popular, Cooperação Federativa e Regime de Colaboração”. O FEE congrega em sua composição, representação de 53 instituições do poder público e da sociedade civil organizada ligadas à Educação.

Nos últimos anos, as ações do EDUCAVALE têm se concentrado no fortalecimento dos conselhos municipais de educação, nos obstáculos que envolvem a implementação do Programa Mais Educação, na reelaboração dos Planos Municipais de Educação, na reestruturação dos Planos de Cargos, Carreira e Remuneração (PCCR), e nas dificuldades enfrentadas pelos municípios para o cumprimento da Lei do Piso Salarial Profissional Nacional (Lei no 11.738/2008). Uma parceria importante para o EDUCAVALE no enfrentamento de alguns problemas elencados, tem sido a da Secretaria de Articulação com os Sistemas de Ensino (SASE), criada em 2011, pelo Ministério da Educação, e que tem como função precípua o desenvolvimento de ações para a criação de um Sistema Nacional de Educação (SNE), cujo prazo final está previsto no artigo 13 da Lei no 13.005, de 25 de junho de 2014 (que aprova o Plano Nacional de Educação (PNE) e dá outras providências). O SNE, segundo o referido dispositivo legal, deverá ser instituído pelo poder público, em lei específica, contados dois anos da publicação do PNE.

\section{Considerações finais}

Como visto, para além dos aspectos que as aproximem ou distanciem, essas duas experiências de associativismo territorial na área de Educação, no estado da Bahia, representam, fundamentalmente, modelos exitosos de organização cooperativa, com forte participação social (principalmente o ADE Chapada) e participação dos profissionais da Educação, mesmo considerando a fragilidade socioeconômica dos Territórios onde as ações foram e/ou estão sendo desenvolvidas.

Em ambos os casos, a escolha por cooperar deu-se a partir da existência de problemas comuns e pela capacidade de coletivamente instrumentalizar respostas. No entanto, o Fórum EDUCAVALE é uma iniciativa que surgiu dos próprios dirigentes de educação e é coordenada por eles, sem qualquer interferência de instituições ou entidades ligadas à iniciativa privada. Julgo este aspecto de grande importância, pois contrasta com o decantado discurso, inclusive largamente usado pelo movimento em- 
presarial do TPE, da ineficiência administrativa das instituições públicas educacionais. Vale ressaltar que as experiências de associativismo, até então identificadas, surgiram a partir da interveniência e indução de parcerias pela iniciativa privada, a saber: ADE Chapada/Bahia (Instituto Natura); Arranjos Pará I e II (Fundação Vale e CEDAC ); $\mathrm{ADE}$ da Estrada de Ferro dos Carajás/Maranhão (Fundação Vale e CEDAC); ADE de Sergipe (Fundação Vale e CEDAC); ADE da Mesorregião de São José do Rio Preto/São Paulo (Banco Santander e CEDAC).

O desenho institucional e o modelo de governança também são distintos entre as duas experiências do estado da Bahia (ADE Chapada e EDUCAVALE). No tocante aos conteúdos de colaboração e cooperação, é possível identificar que, em menor ou maior grau, estão presentes os seguintes aspectos: articulação federativa entre os municípios e destes com outros níveis de governo, ação conjunta regionalizada, e apoio e indução a mudanças no plano local; capacidade de gestão institucional, caracterizada pela reestruturação de secretarias e mecanismos de ligação administrativa com as escolas; modelos de gestão pedagógica, principalmente no acompanhamento de indicadores educacionais e formação/capacitação de professores; instrumentos de transparência e controle social e democrático, que envolve criação de fóruns intergovernamentais, parcerias com entidades não governamentais, mobilização social nos municípios e divulgação de dados educacionais.

Quanto ao aspecto do financiamento, fica evidente que a condição do ADE Chapada, ao tornar-se uma OSCIP, lhe garante fontes de recursos da iniciativa privada (especialmente doações), bem como da administração pública, através de termo de parcerias (subvenção) com os municípios. Já em relação ao Fórum EDUCAVALE, que não tem uma natureza jurídica e que pelas regras do CNE não pode ter acesso a recursos públicos, os compromissos concernentes ao financiamento não estão formalizados, permanecendo sem uma base estável ou clareza quanto aos recursos que podem ser utilizados. O problema em questão pode ser resolvido para além da repartição de responsabilidades financeiras dos municípios envolvidos, necessitando de ações coordenadoras e indutivas da União e dos estados, que no caso da Bahia, no plano intergovernamental, tem um pequeno e inexpressivo papel na articulação federativa com os municípios, a despeito de parcerias diretas e constantes como as existentes entre os estados do Acre, Ceará, Sergipe e Mato Grosso e suas respectivas municipalidades.

Apesar do grande esforço que o ADE Chapada e o Fórum EDUCAVALE vem desenvolvendo para garantir uma educação de qualidade nos municípios, é necessário e oportuno, inclusive pela natureza dos problemas encontrados, trazer para essa discussão, se tratando de relações intergovernamentais num Estado de base federativa, a questão da equalização, que está intimamente ligada ao regime de colaboração, como veremos a seguir.

A questão da equalização, no tocante aos estudos sobre federalismo, representa discutir duas demandas primordiais que são o des-equilíbrio vertical - que diz respeito à distribuição de encargos, competências e recursos entre governo central e governos subnacionais -, e o des-equilíbrio horizontal, que diz respeito às diferenças entre governos subnacionais na capacidade de prestação de serviços públicos (PRADO, 2006). 
Os (des)equilíbrios vertical e horizontal estão diretamente relacionados ao nível de centralização/descentralização das seguintes dimensões: a) gasto-execução das políticas públicas de cada esfera de governo; b) bases próprias de arrecadação de cada esfera de governo; c) montante e forma das transferências intergovernamentais necessárias à execução das políticas públicas. E é exatamente nesta última dimensão, que representa as transferências entre esferas de governo, que reside o problema da equalização: como garantir um padrão mínimo de serviços públicos a cada cidadão da Federação (REZENDE, 2006).

Enquanto para algumas federações, a exemplo dos Estados Unidos, a questão da equalização não é um valor basilar, para outras, incluindo o Brasil, ao levar em consideração as diferentes capacidades econômicas e fiscais por parte dos governos subnacionais, que os incapacitam a lidar com as disparidades em termos de arrecadação e em termos de provisão de bens e serviços públicos, torna-se imperiosa a ação normativa e redistributiva por parte do governo central.

Para Araújo (2013, p. 799), a ação por parte do governo central está condicionada à correlação de forças existentes entre os entes federados e às fórmulas de redistribuição das receitas. Essa correlação de forças entre as unidades subnacionais entre si e com a União, bem como a ação do governo central, devem afluir para a garantia da equalização num Estado federativo de bases cooperativas, tanto no sentido da coordenação quanto no sentido da colaboração federativa, que para a supracitada autora tem a seguinte distinção:

$[\ldots]$ ao passo que a primeira se constitui em procedimento que busca resultado comum a partir do governo central, apesar da autonomia dos entes federados, a colaboração federativa se traduz no modo de atribuições e exercício das competências concorrentes e comuns, devendo a tomada de decisões e o exercício das competências serem conjuntos e não isolados.

Foi justamente para lidar com essa problemática de conjugação entre autonomia e interdependência dos entes federativos que a Carta Magna de 1988 elegeu o regime de colaboração que, num Estado organizado em bases federativas como o nosso, é um dos institutos jurídicos e políticos fundamentais para a garantia da equalização das condições de vida em todo o território.

Ademais, os dispositivos constitucionais vão forjando a dinâmica fundamental do federalismo brasileiro e a imprescindibilidade de regulamentação da cooperação entre os entes federados que, apesar da autonomia que possuem, precisam dar conta de competências privativas, comuns e concorrentes, que não os desconstituirão, mas que devem se consubstanciar por meio de relações de cooperação, tendo como parâmetro a garantia de direitos em âmbito nacional, incluindo, obviamente, uma educação de qualidade.

\section{Referências}

ARAUJO, Gilda Cardoso. Federalismo e políticas educacionais no Brasil: equalização e atuação do empresariado como projetos em disputa para a regulamentação do regime de colaboração. Educação \& Sociedade. Campinas, v. 34, n. 124, Set., 2013. 
BAHIA. Perfil dos Territórios de Identidade da Bahia. Secretaria de Desenvolvimento Rural. Salvador, SDR, 2015.

BRASIL. Constituição da República Federativa do Brasil. Promulgada em 05 de outubro de 1988.

BRASIL. Lei 13.005, de 25 de junho de 2014. Aprova o Plano Nacional de Educação - PNE e dá outras providências. Diário Oficial da União, Brasília, DF, 26 jun, 2014.

JAGUAQUARA. Regimento Interno do Fórum de Secretários de Educação dos Municípios do Vale do Jiquiriçá. 2010.

OLIVEIRA, Cybele Amado de; MEIRELLES, Cristina. Projeto Chapada: uma experiência de ADE na Chapada Diamantina. In: ABRUCIO, Fernando Luiz; RAMOS, Mozart Neves (Org.). Regime de colaboração e associativismo territorial: arranjos de desenvolvimento da Educação. São Paulo: Fundação Santillana, 2012.

PRADO, Sérgio. Equalização e federalismo fiscal: uma análise comparada. Rio de Janeiro: Fundação Konrad Adenauer, 2006.

RELATÓRIO FINANCEIRO ANUAL. Instituto Chapada de Educação e Pesquisa, 2010. Disponível em: <http://www.institutochapada.org.br/wp-content/uploads/2011/12 /Relat\%C3\%B3rio-Financei ro-Anual-2010.pdf> Acesso em: 20 jan. 2016.

RELATÓRIO DE AUDITORIA. Balanço da auditoria relativa ao biênio 2010-2011. Instituto Chapada de Educação e Pesquisa, 2010-2011. Disponível em: <http://www.instituto chapada.org.br/wp-content/uploads/2012/10/Auditoria-Balanc\%C3\%8C\%C2\%A7o-2011-2010. pdf> Acesso em: 20 jan. 2016.

REZENDE, Fernando. Desafios do federalismo fiscal. São Paulo: FGV, 2006.

THOMPSON, John Brookshire. Ideologia e Cultura Moderna: teoria social crítica na era dos meios de comunicação de massa. Petrópolis, RJ: Vozes, 1995.

\section{Notas}

${ }^{1}$ Arranjos de Desenvolvimento da Educação são definidos pelo TPE como um trabalho em rede, no qual um grupo de municípios, com proximidade geográfica e características sociais e econômicas semelhantes, buscam trocar experiências e solucionar conjuntamente dificuldades na área da educação.

* Professor da Universidade Estadual do Sudoeste da Bahia, Jequié, Bahia, Brasil.

** Professor da Universidade do Porto, Portugal.

\section{Correspondência}

Ubirajara Couto Lima - Universidade Estadual do Sudoeste da Bahia, Departamento de Ciências Humanas e Letras. Rua José Moreira Sobrinho, S/N. Jequiezinho. CEP: 45206190. Jequié, Bahia, Brasil.

E-mail: bira.lima@hotmail.com - tiago@fpce.up.pt

Recebido em 27 de maio de 2017

Aprovado em 08 de março de 2018 